\title{
$L_{0}$ Norm 기반의 LE(Local Effect) 연산자를 이용한 디지털 이미지 위변조 검출 기술 개발
}

최용수 $* \dagger$

\section{Development of Digital Image Forgery Detection Method Utilizing LE(Local Effect) Operator based on $L_{0}$ Norm}

\author{
YongSoo Choi*†
}

요 약

디지털 이미지 위조 탐지는 디지털 포렌식 분야에서 매우 중요한 분야 중 하나이다. 기술의 발전을 통해 위조된 이미지가 자연스럽게 바뀜에 따라 이미지 위조를 감지하기 어렵게 만들었다. 본 논문에서는 디지털 이미지에서 복사 붙여넣기 위조에 대한 수동적 위조 검출을 이용한다. 또한, $L_{0}$ Norm 기반 LE 연산자를 사 용해 복사 붙여넣기 위조를 검출함과 동시에 기존에 존재하던 $L_{2}, L_{1}$ Norm 기반 LE 연산자를 이용한 위조 검출 정확도를 비교하였다. 제안한 하삼각 윈도우를 적용하고 $L_{2}, L_{1}$ 및 $L_{0}$ Norm 기반 LE 연산자를 통해 $\mathrm{BAG}$ 불일치를 검출하고 위조 검출률을 측정하였다. 검출률의 비교에서 제안한 하삼각 윈도우는 기존의 윈도 우 필터보다 $\mathrm{BAG}$ 불일치 검출에 강인함을 볼 수 있었다. 또한, 하삼각 윈도우를 쓰는 경우 $L_{2}, L_{1}, L_{0}$ Norm $\mathrm{LE}$ 연산으로 갈수록 이미지 위조 검출의 성능이 점점 높게 측정되었다.

\begin{abstract}
Digital image forgery detection is one of very important fields in the field of digital forensics. As the forged images change naturally through the advancement of technology, it has made it difficult to detect forged images. In this paper, we use passive forgery detection for copy paste forgery in digital images. In addition, it detects copy-paste forgery using the $L_{0}$ Norm-based LE operator, and compares the detection accuracy with the forgery detection using the existing $L_{2}, L_{1}$ Norm-based LE operator. In comparison of detection rates, the proposed lower triangular(Ayalneh and Choi) window was more robust to BAG mismatch detection than the conventional window filter. In addition, in the case of using the lower triangular window, the performance of image forgery detection was measured increasingly higher as the $L_{2}, L_{1}$ and $L_{0}$ Norm LE operator was performed.
\end{abstract}

한글키워드 : 위변조 검출, 복사-붙여넣기, 로컬 효과, 놈 연산자

keywords : Forgery Detection, Copy-Move, Local Effect, Norm Operator

* 신한대학교 기계자동차융합공학과

† 교신저자: 최용수(email: ciechoi@shinhan.ac.kr)
접수일자: 2020.12.07. 심사완료: 2020.12.18.

게재확정: 2020.12.21. 


\section{1. 서 론}

디지털 이미지 위조에는 이미지를 이어 붙이 는 스플라이싱(Splicing), 사진을 보정하는 리터 칭(Retouching), 이미지 일부를 복사해서 붙이는 복사-붙여넣기(Copy-Move) 등이 있다[3, 5, 6, 9]. 위조탐지를 위한 디지털 포렌식 기법에는 검 출 효과는 좋으나 유용성이 떨어지는 능동적 기 법과 검출효과는 다소 낮으나 유용성이 높은 수 동적 기법이 있다[1, 2, 4, 7, 8, 9]. 수동적인 검 출기법인 Block Artifact Grid(BAG)가 많은 논 문들에 의해 참조 되었으며 $\mathrm{LE}$ 연산자를 이용하 여 위변조 검출에 사용되었다. 본 논문에서는 $\mathrm{BAG}$ 의 논리에 근거하고 기존의 $L_{2}, L_{1}$ Norm 연 산자를 개선하기 위해 $L_{0}$ Norm 연산자를 제안 하였고 특이치에 강인하도록 하기 위해 하삼각 윈도우 필터를 적용하여 복사-붙여넣기 위변조 를 검출하고자 한다.

\section{2. 위변조 검출을 위한 배경 지식}

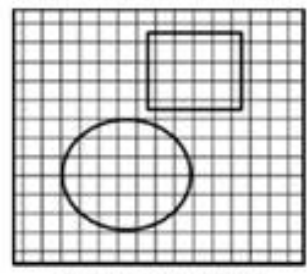

(a) Intact BAG

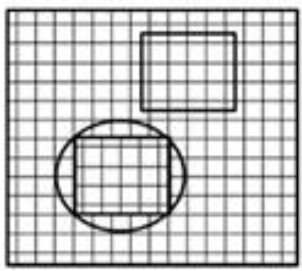

(b) Doctored BAG
그림 1. 복사-붙여넣기 위조 이전과 이후의 $\mathrm{BAG}$ 상태

Fig. 1. BAG plot before and after copy-move forgery

그림 1 과 같이 디지털 이미지의 저장 및 압축 에서 발생하는 그리드의 존재는 원본 이미지의 변화를 측정하는 증거로 사용될 수 있다. 그림 1 에서 수개의 그리드를 포함하는 일부가 복사되고 그림내의 다른 영역에 붙여넣기 되었다면 그림 1(b)과 같이 잘라진 그리드의 모음이 새 위치에 덮어씌워질 것이고 원래 이미지의 그리드와 일치 하지 않는 부분이 생길 것이다.

하지만 그리드는 공간영역에서의 픽셀의 값 으로 존재하는 증거가 아니므로 그리드의 훼 손을 검출하려면 이미지를 공간영역에서 주파 수 영역으로 변환해서 살펴야 한다. 본 논문에 서는 복사-붙여넣기 위조 검출을 하기 위해 위조된 영상을 주파수 영역의 계수로 변환시켰 으며 이때 이산 코사인변환(DCT)을 적용한다.

$$
\begin{aligned}
F(u, v)= & \frac{C(u) C(v)}{4} \sum_{j=0 i=0}^{7} \sum_{i}^{7} f(i, j) \cdot \\
& \cos \frac{(2 i+1) u \pi}{16} \cos \frac{(2 j+1) v \pi}{16}
\end{aligned}
$$

where, $0 \leq u, v<8$ and

$$
C(u)= \begin{cases}\frac{1}{\sqrt{2}}, & u=0 \\ 1 & u>0\end{cases}
$$

영상에서 매 8X8 픽셀블록의 값들은 식(1)의 $\mathrm{DCT}$ 연산을 통해 주파수 영역으로 변환되고 계수들은 그림 2 와 같은 형태로 얻어진다. $8 \times 8$ 블록에서 Bottom-Right 부근에는 0에 가까운 크기의 고주파 성분들이 많이 포함한다. 바로 이러한 0 의 값들이 디지털 영상이 그리드를 형 성하는 것이다. 주파수 영역에서 블록의 경계 를 알려주는 이러한 값들의 특징을 Block Artifact Grid(BAG) 라고 한다.

\begin{tabular}{|l|l|l|l|l|l|l|l|}
\hline .640 & 340 & 146 & 21 & 11 & 11 & 1 & -1 \\
\hline-104 & -82 & 54 & 79 & 39 & -8 & -6 & 3 \\
\hline-4 & -28 & -30 & -18 & 0 & 1 & 5 & -1 \\
\hline-13 & -14 & -6 & -17 & -5 & 0 & 2 & 2 \\
\hline-1 & -6 & -4 & -2 & 1 & 2 & 3 & 1 \\
\hline-2 & -2 & -2 & -1 & 0 & 1 & 1 & 0 \\
\hline-1 & -2 & -2 & -1 & 0 & 1 & 1 & 0 \\
\hline 0 & 0 & 0 & 0 & 0 & 0 & 0 & 0 \\
\hline
\end{tabular}

그림 2. 8X8 DCT 계수블록의 예 Fig. 2. Example of X8 DCT Coefficient Block 
$\mathrm{BAG}$ 는 이미지의 공간 영역에서는 식별이 불 가능하며 그리드의 효과를 증폭 시킴으로서 그리 드의 검출이 가능한데 그리드의 증폭을 위해 Local Effect(LE) 연산자를 사용한다. LE는 지역 (8X8)적 영역의 각 계수 값들이 가지는 상대적 크기를 의미하며 논문에서는 기존의 $\mathrm{LE}$ 연산자 의 적합성을 비교 및 검증하기 위해 $\mathrm{LE}$ 연산자로 서 $L_{2}$ Norm, $L_{1}$ Norm, $L_{0}$ Norm을 사용한다.

$$
L E_{L_{2}}=\sqrt{\frac{\sum_{j=0}^{7} \sum_{i=0}^{7} F^{2}(i, j) W(i, j)}{F^{2}(0,0)}}
$$

$L_{2}$ Norm을 이용한 LE계산은 DCT된 8x8 블 록의 계수들을 식(2)을 이용해 계산된다. 여기 서 $\mathrm{W}$ 는 $8 \times 8$ 계수 블록의 가중치 필터로서 해 당 위치의 계수값의 보존을 특정하게 된다.

\begin{tabular}{|l|l|l|l|l|l|l|l|}
\hline 1 & 0 & 0 & 0 & 0 & 0 & 0 & 1 \\
\hline 0 & 0 & 0 & 0 & 0 & 0 & 0 & 1 \\
\hline 0 & 0 & 0 & 0 & 0 & 0 & 0 & 1 \\
\hline 0 & 0 & 0 & 0 & 0 & 0 & 0 & 1 \\
\hline 0 & 0 & 0 & 0 & 0 & 0 & 0 & 1 \\
\hline 0 & 0 & 0 & 0 & 0 & 0 & 0 & 1 \\
\hline 0 & 0 & 0 & 0 & 0 & 0 & 0 & 1 \\
\hline 1 & 1 & 1 & 1 & 1 & 1 & 1 & 1 \\
\hline
\end{tabular}

\begin{tabular}{|c|c|c|c|c|c|c|c|}
\hline 1 & 0 & 0 & 0 & 0 & 0 & 0 & 1 \\
\hline 0 & 0 & 0 & 0 & 0 & 0 & 1 & 1 \\
\hline 0 & 0 & 0 & 0 & 0 & 1 & 1 & 1 \\
\hline 0 & 0 & 0 & 0 & 1 & 1 & 1 & 1 \\
\hline 0 & 0 & 0 & 1 & 1 & 1 & 1 & 1 \\
\hline 0 & 0 & 1 & 1 & 1 & 1 & 1 & 1 \\
\hline 0 & 1 & 1 & 1 & 1 & 1 & 1 & 1 \\
\hline 1 & 1 & 1 & 1 & 1 & 1 & 1 & 1 \\
\hline
\end{tabular}

(a) Li Window (b) Ayalneh and Choi Window 그림 3. $8 \times 8 \mathrm{DCT}$ 계수 블록에 적용되는 윈도우 필터

Fig. 3. Window Filter adopted to $8 \times 8$ DCT coefficients Block

기존의 논문들은 $\mathrm{LE}$ 의 연산에 있어 그림 3(a)의 필터를 윈도우 필터로 사용하였으나 제 안된 논문에서는 오류에 강인한 $\mathrm{LE}$ 연산을 위 해 그림 3(b)과 같은 하삼각 Window를 사용하 였다. $L_{2}$ Norm LE계산은 영상의 복잡도에 따
른 의존도가 높아 특이치가 많은 복잡한 이미 지에 적용할 경우 검출 오류가 발생할 수 있 다. 복잡도가 높은 영상에서는 특이치(Outlier) 에 의한 오차의 영향이 제곱이 되므로 특이치 에 매우 민감함을 예측할 수 있다.

Norm기반의 LE 연산을 이용한 위조 검출은 크게 두 그룹에서 연구를 수행하였다. $\mathrm{Li}$ et. al 등은 DCT변환 후의 블록의 계수들은 양자 화로 인해 마지막 행과 마지막 열에서 0 또는 매우 작은 값 계수를 갖는다는 가정을 하였으 며 그림 3(a)와 같이 윈도우의 마지막 행과 마 지막 열의 $\mathrm{DCT}$ 계수만을 복원하는 Window를 Norm기반 LE연산에 적용했다[1]. Ayalneh and Choi 등의 연구진은 그림 3(b)와 같이 하삼각 대각행렬 영역에서 하한 삼각형의 DCT계수를 사용하는 Window를 Norm LE 연산에 적용했 다[2].

$$
\begin{aligned}
& L E_{L_{1}}=\sum_{j=0}^{7} \sum_{i=0}^{7}[|F(i, j)| W(i, j)] \\
& L E_{L_{0}}=\sum_{j=0}^{7} \sum_{i=0}^{7}[\operatorname{card}(\lfloor F(i, j) W(i, j)\rfloor)] \\
& \text { if }\lfloor F(i, j)\rfloor \neq 0
\end{aligned}
$$

$L_{1}$ Norm을 이용한 LE 연산은 식(3)과 같으며 $L_{0}$ Norm을 이용한 LE 연산은 식(4)를 설계하였 으며 식(4)는 고주파 성분이 많은 복잡한 이미지 의 특이치에 대한 의존도가 낮아 $L_{2}$ 그리고 $L_{1}$ Norm에 비해 특이치에 민감하지 않으며 계산속 도도 빠른 특성을 가진다. 특히 $L_{0}$ Norm은 특 이치에 더 강인하며 전체 Window를 사용할 때 $L_{2}$ 그리고 $L_{1}$ Norm에 비해 최대 성능을 제공한 다. 본 논문에서는 기존의 두 가지 $\mathrm{LE}$ 와 제안된 $L_{0}$ Norm 계산 방법에 의한 위조 검출 정확도를 비교한다. 


\section{3. 제안하는 위변조 검출 알고리즘}

\section{1 위변조 검출 시스템 프로세스}

실제 위조검출의 각 모듈들에 대한 설명은 3.1.1절에서 자세히 전개하고 위조 검출 과정을 다음의 과정으로 수행됨을 간단히 제시하였다.

1) 입력 영상에 대해 블록별로 2-DCT를 수행

2) 각 픽셀별로 $\mathrm{LE}$ 값을 추출

3) $\mathrm{LE}$ 값들을 기반으로 $\mathrm{BAG}$ 평면도를 작성

4) $\mathrm{BAG}$ 부정합인 곳들을 검출

5) $\mathrm{BAG}$ 부정합 판단 픽셀들을 군집화

6) 해당 영역을 위조 영역으로 판단하고 검출 을 종료

\subsubsection{LE 특성치 검출}

$\mathrm{LE}$ 값의 연산은 제안하는 알고리즘의 핵심 영역이며 영상전체에 대한 $\mathrm{LE}$ 를 구하기 위해 이미지 전체에 걸쳐 $8 \times 8$ Window Filter를 사용 하여 회선기법에 따라 연산한다. 식 (1)에 따 라 $L_{0}$ Norm은 위에서 설명한 것과 같이 $8 \times 8$ DCT행렬에서 0 이 아닌 계수의 수를 계산한다. 0 이 계수가 많을수록 원래의 블록에지에 다른 값들이 포함되어 있음을 예측할 수 있다. 그림 4 에서는 영상전체에 대한 LE측정치의 결과를 일부 확대하였다. 그림과 같이 그리드의 존재 를 확인 할 수 있으며 검출된 그리드와 기존 그리드가 일치하는 곳에서는 $\mathrm{LE}$ 가 최솟값을 가지고 일치하지 않는 곳은 밝은(큰) 값으로 나타난다.

\subsubsection{BAG CONSTRUCTION}

3.1.1절에서는 $\mathrm{LE}$ 값을 영상으로 보임으로써 실제 그리드를 검출 할 수 있음을 시각적으로 보였다. 불일치 그리드를 검출하기 위해 LE 행 렬을 다시 $8 \times 8$ 블록으로 분할한 후 각 블록마

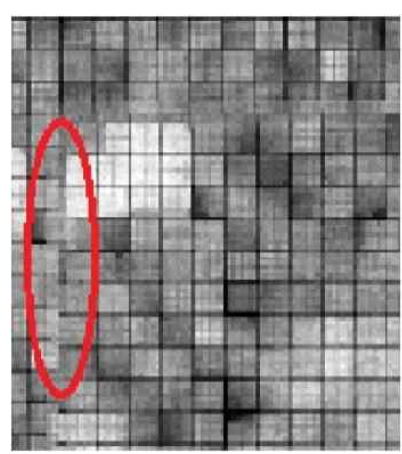

그림 4. LE값의 출력영상 확대

Fig. 4. Expansion of Output Image of LE Values

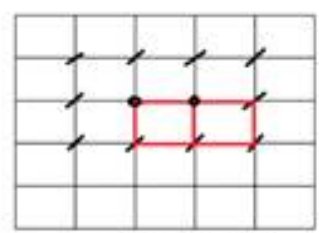

(a) Horizontal

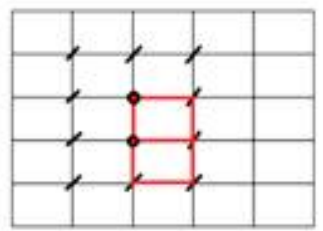

(b) Vertical
그림 5. LE값의 출력영상 확대 블록 주변의 그리드 존재 결정 예시

Fig. 5. Example for Decision of existence of grid around a block.

다 local minima가 하나씩 존재한다고 가정하 고, 두 개의 인접 블록 주위에 그리드의 존재 를 확인할 때 마다 블록마다 local minima를 표시한다. 만약 그림5과 같이 인접한 두 블록 의 local minima 2 개가 수직 또는 수평으로 서 로 매 8 픽셀 거리에 위치한 경우 해당 블록 주위에 $\mathrm{BAG}$ 가 발생했을 가능성이 높다고 볼 수 있다. 하지만, 원본이미지가 가진 강한 엣 지들의 시각적 패턴으로 그리드 검출의 오류 를 증가시키기도 한다. 이를 해결하기 위해 본 논문에서는" - "로 표시한 수직, 수평으로 연속된 2개의 local minima와 "/"로 표시한 부분에 세 번째 local minima가 존재할 때 사 
각 그리드를 그리도록 알고리즘을 개선하였다. 복사-붙여넣기 위조가 된 이미지는 이 과정을 거치면 그림 $6(\mathrm{a})$ 처럼 일치하는 그리드와 일치 하지 않는 그리드가 함께 검출된다.

\subsubsection{BAG MISMATCH DETECTION}

$\mathrm{BAG}$ 는 원본 이미지와 일치하거나 일치하지 않을 수 있다. 일치하는 $\mathrm{BAG}$ 는 영상의 수직 및 수평 가장자리로부터 8픽셀 배수에 위치한다. 기본 이미지의 $\mathrm{BAG}$ 와 정합하지 않는 $\mathrm{BAG}$ 는 일 치하지 않는 $\mathrm{Grid}($ 격자)로 간주된다. $\mathrm{BAG}$ 검출 알고리즘에서 일치하는 $\mathrm{BAG}$ 는 격자의 왼쪽 상 단 모서리에 점으로 표시되고, 일치하지 않는 격 자는 보존한다.

그림 10 의 중간 그림은 불일치 $\mathrm{BAG}$ 검출 후 일치하는 격자와 일치하지 않는 격자가 나타남을 보여준다. 좌측 하단부를 제외한 외부 격자는 기 본 이미지와 정렬되지만 좌측 하단부 격자는 정 렬되지 않는다. 따라서, 알고리즘은 좌측 하단부 영역을 불일치 격자로 선언한다. 그림 6(a)는 일 치하지 않는 격자를 확대해 놓은 것이다. 검출 알고리즘에서 일치된 $\mathrm{BAG}$ 는 격자의 왼쪽 상단 모서리에 점으로 표시되고, 일치하지 않는 격자 는 어두운 선으로 표시하여 가시성을 높인다. 그 림 6(b)가 그 결과를 나타낸다.

\subsubsection{FORGERY LOCALIZATION}

검출 알고리즘의 마지막 단계에서는 위조여부 판단용 테스트 이미지에에 대한 부정합 $\mathrm{BAG}$ 를 찾고 이 정보를 테스트 영상에 오버랩함으로써 위조영역에 대한 표시가 가능하다. 특히, 이웃하 는 mismatch $\mathrm{BAG}$ 들을 군집화 함으로써 위조 영역에 대한 외곽선으로 표시하는 것도 가능하 다. 이 결과는 그림 10 의 오른쪽 끝의 그림처럼 블로킹하여 보여준다.

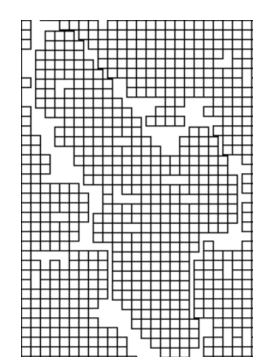

(a)

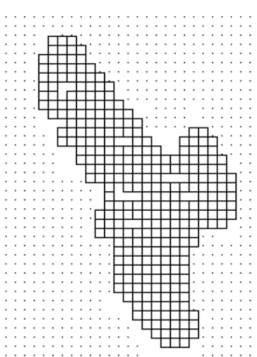

(b)
그림 6. 불일치 $\mathrm{BAG}$ 검출과 영역화

Fig. 6. Detection and Localizing of mismatch BAG

\section{4. 실험결과 및 분석}

제안된 위조영역 검출 알고리즘은 네 가지의 $\mathrm{LE}$ 연산자를 사용하여 구현하였다. 그 중 두 가지 는 $\mathrm{Li}$ et. al.에서 제시한 윈도우 필터를 사용하였 고 나머지는 Ayalneh and Choi에서 제시한 하삼 각 윈도우 필터를 사용하였다. Li et. al. 윈도우에 는 $L_{2}$ Norm 연산자를 적용하여 검출을 수행하였 고 Ayalneh and Choi 윈도우에 대해서는 $L_{2}, L_{1}$, $L_{0}$ Norm 연산자를 이용하여 LE를 연산하였다.

첫 번째 실험에서는 객관적인 우수성을 검증 하기 위해 두 가지 윈도우 필터에 Norm 기반 $\mathrm{LE}$ 값들을 통한 위조 검출을 수행하여 정확성을 비교하였다. 두 번째 실험에서는 각 Norm에 새 로운 윈도우를 적용시켰을 때 더 좋은 검출률을 보이는지 실험하였다.

\subsection{ACCURACY COMPARISON FOR EACH NORM}

위변조 검출 알고리즘은 Visual Studio에서 작 성되었으며 검출고리즘은 위조된 이미지 데이터 베이스에서 선택한 영상들을 사용하였다. 그리고 윈도우 필터와 Norm 연사자를 조합하는 네 가지 알고리즘을 선택영상을 적용하여 정확도를 측정 하였다. 
그림 11 은 제시한 4 가지 접근방법에 의해 검출 된 실험결과를 도시해준다. 표 1 에서 ' $*$ ’로 표시 된 이미지는 복잡한 이미지이며 특이치에 민감하 므로 $L_{2}$ Norm에서 민감하게 반응한다. 그 반면 $L_{1}, L_{0}$ Norm은 이미지의 복잡도에 따라 둔감하 게 반응함을 알 수 있다.

표 1에서 볼 수 있듯이 $L_{1}$ Norm이 항상 $L_{2}$ Norm보다 검출 성능이 좋은 것은 아니다. Field, Bird 이미지의 경우 $L_{1}$ Norm을 통한 위조 검출 보다 Ayalneh and Choi의 Window를 사용한 $L_{2}$ Norm의 위조 검출 성능이 좋게 검출된다. 즉, $L_{2}$ Norm은 특이치에 민감하기 때문이며, 전체영 상을 대상으로 $\mathrm{Li}$ Window를 사용하는 검출과 Ayalneh and Choi Window를 사용하는 검출의 평균을 비교해보면 $\mathrm{Li}$ 윈도우의 검출 결과가 더 좋다. 하지만 Bird, Beach, Field 이미지에서의 검 출 성능은 Ayalneh and Choi Window를 사용한 것이 더 높은 검출 성능을 보여준다.

표 1. 윈도우별, 각 Norm 연산자별 검출률 Table 1. 영 Detection Rate of Each Norm Operator and Each Window

\begin{tabular}{|c|c|c|c|c|}
\hline \multirow{3}{*}{$\begin{array}{c}\text { Test } \\
\text { Images }\end{array}$} & \multicolumn{4}{|c|}{ Accuracy } \\
\hline & \multicolumn{2}{|c|}{$L_{2}$ Norm } & $\begin{array}{c}L_{1} \text { Nor } \\
\mathrm{m}\end{array}$ & $\begin{array}{c}L_{0} \\
\text { Norm }\end{array}$ \\
\hline & $\mathrm{Li}$ & \multicolumn{3}{|c|}{ Ayalneh and Choi } \\
\hline Bird & 0.4656 & 0.7791 & 0.7607 & 0.9417 \\
\hline Rock* & 0.4813 & 0.0954 & 0.4751 & 0.7199 \\
\hline Beach & 0.8299 & 0.8429 & 0.7651 & 0.9352 \\
\hline Wall* & 0.0492 & 0.0433 & 0.5932 & 0.9871 \\
\hline Bike* & 0.6280 & 0.1219 & 0.8231 & 0.9329 \\
\hline Field & 0.7409 & 0.9036 & 0.897 & 0.9457 \\
\hline Laundry & 0.5482 & 0.5532 & 0.6725 & 0.9771 \\
\hline Church* & 0.4876 & 0.4629 & 0.4753 & 0.6296 \\
\hline
\end{tabular}

그림 11 은 저주파성분이 많은 이미지에서의 각 Norm 연산자별 위조 검출 결과를 도시하였 다. 표에서 보인 실험 결과처럼 $\operatorname{Bird}$ 이미지에 서는 그림 $11(\mathrm{~d})$ 보다 그림 $11(\mathrm{c})$ 가 더 명확한 검 출을 수행한 것을 알 수 있다. 반대로, 복잡한 이 미지인 Wall 이미지에 대한 검출 결과를 보면 그 림 $12(\mathrm{c})$ 와 그림 $12(\mathrm{~d})$ 의 위조 검출 성능이 훨씬 낮은 것을 확인할 수 있다.

실험의 결과들을 요약하면, 제안한 윈도우 필 터를 적용한 그림 $12(\mathrm{~d})$ 와 본 논문에서 고안한 $L_{0}$ Norm 연산자를 적용한 결과인 그림 $12(\mathrm{e})$ 는 이미지의 복잡도에 상관없이 검출 능력이 좋은 것을 확인할 수 있다.

\subsection{ACCURACY COMPARISON OF EACH NORMA FOR EACH WINDOW}

각 윈도우에 따른 Norm의 효용성을 확인하기 위해 다음의 실험을 수행하였다. $\mathrm{Li}$ et. al. Window는 $L_{2} \quad$ Norm연산자를 적용하였고 Ayalneh and Choi 윈도우에서는 $L_{1}$ Norm을 적 용했고 두 개의 윈도우 모두에 $L_{0}$ Norm을 적용 하고 평균을 구하였다. 제시한 세가지 경우를 그래프에서 각각 Li Window, Ayalneh and Choi Window, All Window로 표기하였다. 이 실험에 는 12 개의 테스트 이미지에 대해 검출률을 측정 하였다. 테스트 이미지는 복잡한 이미지와 부드 러운 이미지가 있다. 이미지의 복잡도에 따라 $L_{2}$ Norm은 Window별 정확도 비교의 신뢰도가 떨 어질 수 있지만 $L_{1}, L_{0}$ Norm은 이미지의 복잡도 에 민감하지 않기 때문에 신뢰도가 높을 것으로 예측된다.

$L_{2}$ Norm에서 각 Window별 검출능력의 평균 을 계산한 결과 All window에서 검출 능력의 정 확도 평균은 0.2665, Ayalneh and Choi window 에서 정확도 평균은 $0.2767, \mathrm{Li}$ window에서 정확 도 평균은 0.4379 이 나왔다. 그림 11 을 확인해보면 
대체로 $\mathrm{Li}$ Window를 이용한 $L_{2}$ Norm이 높은 걸 알 수 있다. 그러나 이미지 1과 같이 Ayalneh and Choi Window를 사용한 계산이 더 높을 수 도 있다는 것을 보여준다. $L_{2}$ Norm은 이미지의 복잡도에 너무 민감하기 때문에 신뢰도가 떨어지 는 그래프라고 볼 수 있다.

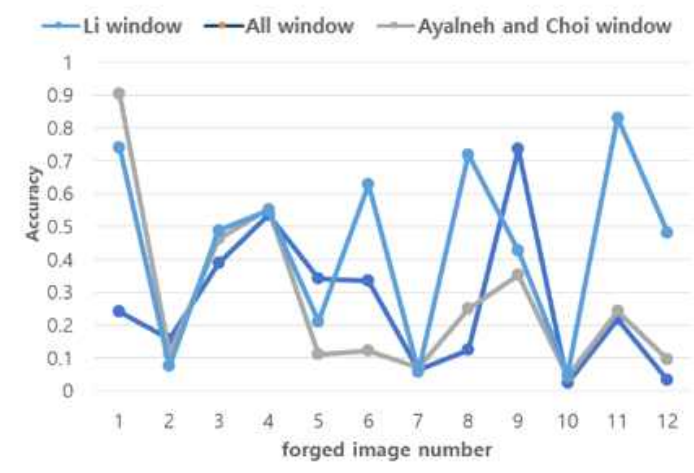

그림 7. 각 윈도우 필터에서 $L_{2}$ Norm의 측정

Fig. 7. Calculation of $L_{2}$ Norm for each window filter

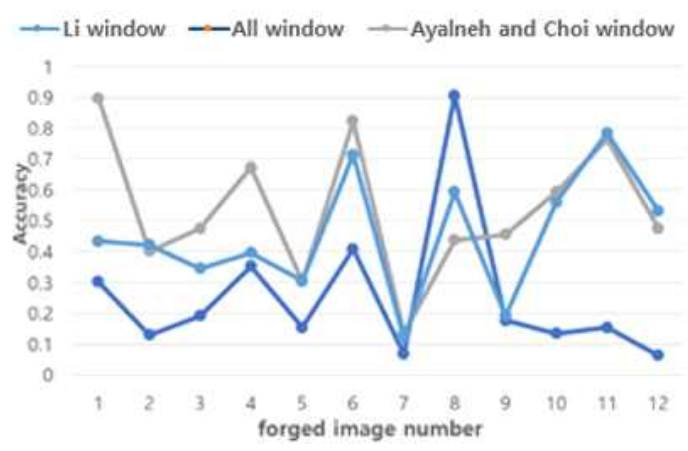

그림 8. 각 윈도우 필터에서 $L_{1}$ Norm의 측정

Fig. 8. Calculation of $L_{1}$ Norm for each window filter

$L_{1}$ Norm에서 각 Window별 검출능력의 평균 을 계산한 결과 All window에서 검출 능력의 정 확도 평균은 0.2531, Ayalneh and Choi window 에서 정확도 평균은 $0.5360, \mathrm{Li}$ window에서 정확 도 평균은 0.4499 가 나왔다. $L_{1}$ Norm에서도
Ayalneh and Choi Window를 사용하는 것이 제 일 정확도가 높게 나왔다. 그러나 이미지 8, 12번 처럼 이미지의 특이치가 가끔 영향을 끼칠 경우 가 있다.

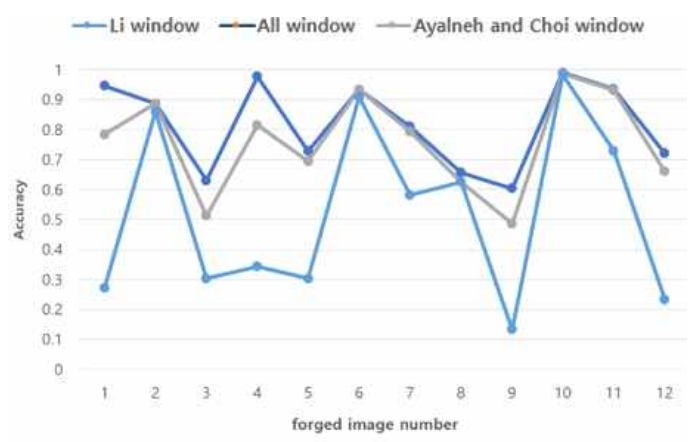

그림 9. 각 윈도우 필터에서 $L_{0} \quad \mathrm{Norm}$ 의 측정 Fig. 9. Calculation of $L_{0}$ Norm for each window filter

$L_{0}$ Norm에서 각 Window별 검출능력의 평균 을 계산한 결과 All window에서 검출 능력의 정 확도 평균은 0.81620, Ayalneh and Choi window 에서 정확도 평균은 $0.76025, \mathrm{Li}$ window에서 정 확도 평균은 0.52238 이 나왔다. $L_{0}$ Norm은 다른 Norm들과 다르게 위조 검출 정확도가 상당히 높 게 나오며 모든 이미지에서 All Window를 사용 하는 것이 검출 능력이 좋음을 알 수 있다. 또 한, 고주파 영역을 계수들을 복원하는 윈도우 필터를 사용할수록 성능이 더 좋다는 것을 알 수 있다. 즉, 특이치에 대한 영향을 거의 받지 않는 것을 알 수 있다.

\section{5. 결론 및 향후 연구}

복사-붙여넣기 위조를 한 디지털 이미지에서 는 $\mathrm{BAG}$ 를 추출하고 격자에서 일치하지 않는 영 역을 검출하는 것이 위조의 증거로 사용될 수 있 었다. BAG 추출 알고리즘은 Local Effect 연산자 


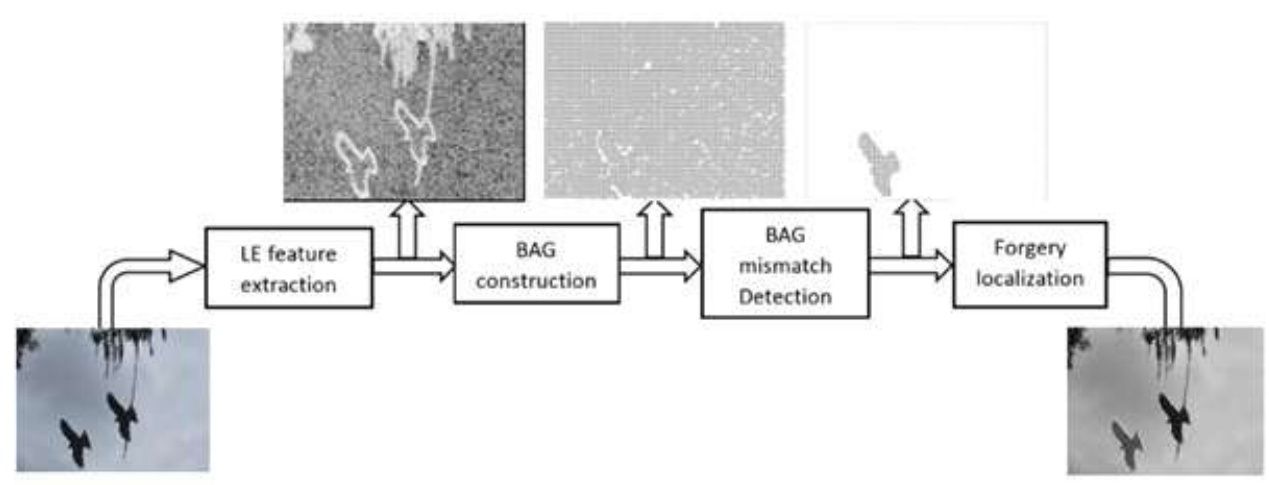

그림 10. 각 윈도우 필터에서 $L_{0}$ Norm의 측정 부드러운 영상에서 각 Norm연산자의 출력 Fig. 10. Calculation of $L_{0}$ Norm for each window filter
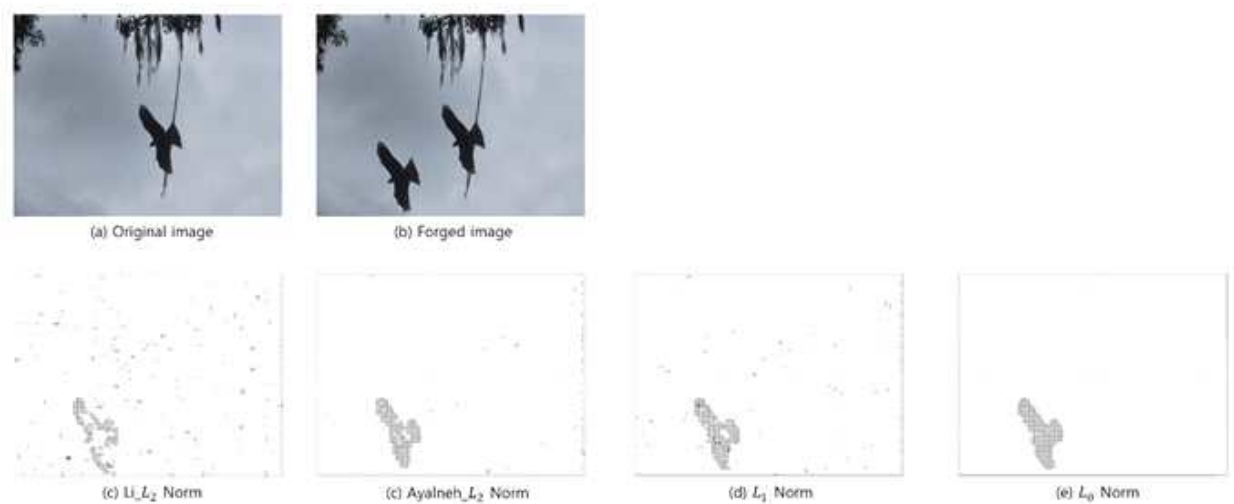

그림 11. 부드러운 영상에서 각 Norm연산자의 출력

Fig. 11. Output of each operator for smooth(low frequency) image
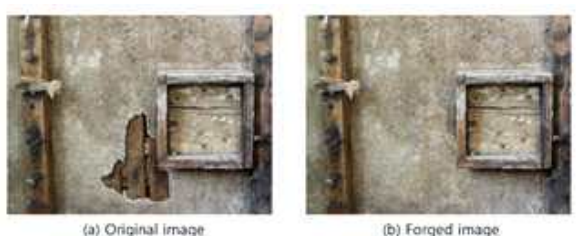

(b) Forged imige

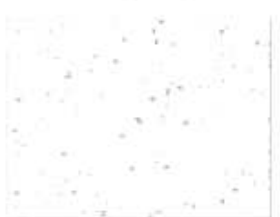

(c) $L_{-} L_{2}$ Norm
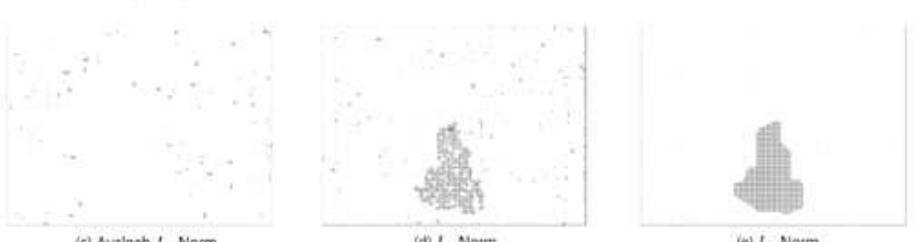

(di) $L_{1}$ Norm

(e) $L_{0}$ Norm

그림 12. 복잡한 영상에서 각 Norm연산자의 출력

Fig. 12. Output of each operator for complex(high frequency) image 
를 사용하여 격자 효과를 증폭한다. 기존의 방법 에서는 $\mathrm{LE}$ 를 계산하기 위해 $L_{2}$ Norm 기반 접 근법이 사용되었다. 이 접근방식은 복잡도가 높 은 이미지에서 $\mathrm{DCT}$ 계수에 의한 특이치가 존재 하기 때문에 $L_{2}$ Norm은 특이치에 민감하게 반 응한다. 본 논문에서는 첫째로, $\mathrm{LE}$ 연산의 $L_{1}$ Norm 및 $L_{0}$ Norm 기반 접근법을 제안하였으며 다양한 종류의 영상에 대해 테스트하여 제안 $\mathrm{LE}$ 연산자의 효용성을 검증하였다. 실험 결과를 통 해 $L_{0} \mathrm{Norm}$ 기반 $\mathrm{LE}$ 연산자가 모든 테스트 이미 지에 대해 다른 Norm 연산자보다 우수함을 보 였다. $L_{0}$ Norm 연산자의 가장 중요한 특징은 $L_{1}$ Norm 및 $L_{2}$ Norm에 비해 특이치에 대해 견고 하다는 것이다. 둘째로, $\mathrm{LE}$ 계산에서 Window 종 류에 따른 검출률을 분석하였으며 알고리즘의 성 능을 극대화하는 Window의 선택을 위한 결과 를 제시하였다. 모든 Norm에 대해 기존에 제시 된 윈도우 필터보다 제안한 논문의 하삼각 윈도 우 필터가 안정적이고 높은 성능을 보임을 확인 하였다.

제안 논문의 실험결과에서 일부 이미지에서 복잡도에 따라 특이치에 따른 윈도우 필터별 검 출률이 측정되었다. 향후 연구에서는 이미지의 주파수영역 값들에 대한 대역별 분류를 통해 적 응적인 윈도우 필터를 적용한다면 검출률의 개선 을 도출할 수 있을 것이다.

\footnotetext{
"본 논문은 2020년도 신한대학교 학술연구비 지원으로 연구되었음."

“이 논문은 2017년도 정부(교육부)의 재원으 로 한국연구재단의 지원을 받아 수행된 기초 연구사업임 (No. NRF-2017R1D1A1B0303146 5)"
}

\section{참 고 문 헌}

[1] Ayalneh. Dessalegn Atnaf'u, Hyoung Joong Kim, and Yong Soo Choi, "JPEG copy paste forgery detection using BAG optimized for complex images", 16th Int'1 Conference on Advanced Communication Technology, 2014. https://https://doi.org/ 10.1109/ICACT.2014.6778945

[2] D. Tralic, J. Petrovic, S. Grgic, "JPEG Image Tampering Detection Using Blocking Artifacts", 19th International Conference on Systems, Signals and Image Processing (IWSSIP), p. 5-8, 2012. https://www.researchgate.net/publication/26 1333661

[3] H. Farid, "A Survey of Image Forgery Detection”, IEEE signal processing magazine, 2009. https://doi.org/10.1109/ WiSPNET.2016.7566257

[4] Li, Weihai, Yuan Yuan, and Nenghai Yu, "Passive detection of doctored JPEG image via block artifact grid extraction", Signal Processing, Vol. 89, No. 9, pp. 1821-1829, 2009. https://doi.org/10.1016/j.sigpro.2009.03. 025

[5] Mishra, Minati, and Flt Lt. and M. C. Adhitary, "Digital Image Tamper Detection Techniques - A Comprehensive Study", ANSVESA, Vol. 7, No. 2, pp. 105-115, 2012. https://arxiv.org/abs/1306.6737

[6] Sacchi, Dario LM, Franca Agnoli, and Elizabeth F. Lofnrs, "Changing history: Doctored photographs affect memory for past public events", Applied Cognitive Psychology, Vol. 21, No. 8, pp. 1005-1022, 2007. https://doi.org/10.1002/acp.1394

[7] W. Li, Y. Yuan, N. Yu, "Detecting copy-paste forgery of JPEG via block atrifact grid extraction", MOE-Microsoft Key Laboratory of Multimedia Computing and Communication, 2007. http://citeseerx. ist.psu.edu/viewdoc/citations?doi=10.1.1.186. 
6194

[8] X. Wang, Li-xian Jiao, Panpan Niu, "Copy-move forgery detection based on compact color content descriptor and Delaunay triangle matching", Multimedia Tools and Applications, 2018. https://doi.org/10.1007/s11042-018-6354-1

\section{저 자 소 개}

최용수 (YongSoo Choi)

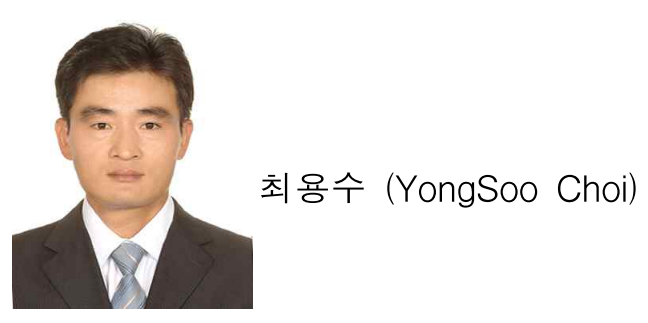

1998년 강원대 제어계측공학과 공학사 2000년 강원대 제어계측공학과 공학석사 2006년 강원대 제어계측공학과 공학박사 2006년 2007년 연세대학교 첨단융합건설 연구단 연구교수.

2007년 2013년 고려대학교 정보보호대학 원 연구교수.

2013년 2020년 성결대학교 파이데이아대 학(멀티미디어) 조교수

2020년 현재 신한대학교 기계자동차융합 공학과 조교수

<주관심분야> Digital Forensics, Information Hiding, Multimedia Watermarking, Steganography 